\title{
An Analysis of the Similarities and Differences of Chinese and Western Female Consciousness and the Roots
}

\author{
Na Meng \\ School of Foreign Languages, Anshan Normal University, Anshan, China \\ 69524164@qq.com
}

Keywords: Chinese and western; Female consciousness; Similarities and differences; Roots

\begin{abstract}
With the development of economy and the progress of the times, cross-cultural communication between China and the West are increasingly frequent. At the same time, female consciousness is booming and far-reaching in China. However, due to the differences between the historical background and traditional culture of China and the West, there is a clear difference between Chinese and Western female consciousness on the basis of commonalities. Based on the analysis of the similarities and differences between Chinese and western female consciousness, this article explores the roots of differences. It aims to study the characteristics of Chinese and western female consciousness from the perspectives of Chinese and Western cultural communication to promote mutual exchange and integration and achieve the harmony of women and the world.
\end{abstract}

\section{Introduction}

Throughout the history of human literature, according to the Chinese Nuwa legend of creating human beings and the appearance of Adam and Eve in the Western Bible, men and women are always closely related and coexist. However, the status of women has always been inferior to that of men. Women in China and the West have always been facing the unequal status in the society and the social reality of being exploited.

With the continuous development of economic globalization, cultural communication among countries is becoming more frequent. In the process of pursuing independent and equal social status, Chinese and western women in China and the west influence each other in female consciousness which is a part of culture. However, due to the different cultural values and social background between China and the west, there are also significant differences between Chinese and Western women's consciousness. Based on the analysis of the similarities and differences between Chinese and western female consciousness in the perspective of intercultural communication, this article further analyzes the reasons for the differences between Chinese and western female consciousness. It tries to seek the suitable way for the women to achieve equal and independent identity by the intercultural Communication of feminism.

\section{The Commonalities of Chinese and Western Female Consciousness}

Chinese and Western Women's Pursuit of Equal Social Status. The prerequisite for equal status between men and women should be mutual understanding, mutual respect and the establishment of a harmonious relationship of equality and mutual trust. However, in fact, throughout the history of mankind, both Chinese and western women have been in an unequal position, suffering male's domination and oppression.

For thousands of years, the world has been dominated by male. In China's ancient and even modern times, women did not have the ability and the right to express their own wishes. They put their own destinies in the hands of men completely. Before they married, their fates were decided by their fathers or elder brothers; after they married, their fates were completely given to their husbands. In the $18^{\text {th }}$-century Britain, although the state was already in a period of transformation from agriculture to industry, the repression of women in the patriarchal society continued. The women relied on the marriage to change their own destinies. James Fortis said: "Nature does not seem to give women the energy as much as a man in creating the women" [1]. 
Whether in China or in the West, the main reason that women are subject to men is that women are imprisoned in their family lives without getting in touch with the outside world. In order to achieve equal social status, Chinese and western women undoubtedly need to get rid of the control of men firstly and look for the opportunities to enter the society. Only by entering the community and gaining a place in the community can women seek the equal opportunities with men.

Chinese and Western Women's Efforts of Gaining the Independence in Economy and Ideology. The formation of female consciousness is primarily ideological and then put it into action. Therefore, in order to achieve the ultimate equality between men and women, women in China and the West should firstly seek the independence of their minds and realize their own values without being dominated by the minds of men, which seems to be simple, but it has gone through a long process. In ancient China, under the influence of feudalism, the ideology that innocence is the virtue for women was deeply rooted. Therefore, there were few opportunities for women to receive education, which undoubtedly provided a barrier to the independence of women's thinking. In western countries, women also face the difficult situation of realizing independence of thoughts. Even with a certain education, women are still willing to rely on marriage to make a living. Therefore, when they are consciously aware of the current situation of inequality between men and women, women in China and the west spontaneously get rid of the domination of patriarchy and pursue the embodiment of self-existence and self-worth.

The economic independence is the guarantee of independent ideology. Only when women realize economic independence and their lives are not controlled by men can they truly achieve their own emancipation and pursue their social and family status. In her A Room of One's Own, Virginia Woolf called on women to have their own private space for freedom of writing. The expanded meaning of this sentence is that women must have their own private property in order to have the right of freedom [2]. When independent thinking is truly translated into the independent economic sources, the independent personality can be embodied and the social status of equality between men and women can be realized.

\section{The Differences between Chinese and Western Female Consciousness}

Chinese Women with a Strong Collective Consciousness and Western Women with a Strong Personal Consciousness. The differences between Chinese and Western cultures lead to the existence of different characteristics in both Chinese and Western female consciousness. The values in Chinese culture pay more attention to groups rather than individuals. The development of Chinese female consciousness also relies on the common goal of the group. Therefore, in the process of realizing female self-worth, Chinese women usually strive for their equality and independence indirectly, and emphasize the overall status of women in social status. Chinese women are more likely to find their own sense of belonging in society. On the contrary, the reflection of individual differences is relatively weaker.

In Western culture, people care more about the manifestation of self-worth. They advocate self-promotion and aim to realize self-worth. Therefore, the way of doing things is even more direct. Western women are more inclined to find their own value by their own efforts because of their strong sense of presence. Western women's self-awareness and self-worth have been fully reflected.

Chinese Women Emphasizing Tradition and Western Women Pursuing B reakthrough. The feminist thoughts in China have gradually developed in the past few centuries. The earliest original feminist thoughts can be found in Tao Te Ching which is very famous philosophical writing in China. Chinese Taoism advocates gender equality which is embodied in the Taoist concept of yin and yang. According to this concept, male is Yang and female is Yin. Both of them are complementary, interdependent, independent and equal. One cannot exist without the other. Both are indispensable in creating and sustaining life. Therefore, the female consciousness in China emphasizes the equality with men by pursuing the mutual complement of identities and mutual cooperation in society and family so as to achieve the harmonious development of male and female [3].

Western women often get rid of the shackles of ideas in social life and to seek their own values 
according to their inner feelings because of the strong sense of self-identity. The satisfaction and practice of self-worth are considered at first in the western culture. Recalling the history of British women, in the period of the late 19th and early 20th centuries, the main feature of feminism was the struggle for political and social rights [4]. In the continuous development of female consciousness, the rationality of western women is far higher than sensibility. They try to find a breakthrough of women's new status in society and family through their own efforts.

\section{The Roots of the Differences between Chinese and Western Female Consciousness}

Women's Self-development Hindered by the Traditional Chinese Concept. Looking at the Confucian view of women from the perspective of family and society, we find that Confucian scholars place the women entirely in a social model that men work outside and women take care of the home inside [5]. The traditional cultural concept makes women ignore the individual's demands. It is difficult to achieve the legitimate rights and interests of individuals. Although The Second Sex was translated into Chinese in the 1980s, its influence was minimal. Li Xiaojiang pointed out that the book's influence is its title rather than its content for the majority of Chinese readers [6].

There is a Chinese proverb that marring a wealthy husband is more important than working hard. Women regard marriage as the second reincarnation of their own life. When women take their hopes and dreams on others, even if who is her closest person, they become lost. However, this sustenance is very risky. Although these women have such a strong sense of femininity, they have never put it into actions. Therefore, Chinese women should further develop their personal consciousness while paying attention to collective awareness. Women should truly respect their inner desires and enjoy the granted rights in society and life to realize the independence of their personality.

Women's More Responsibilities and Obligations Led by the Allocation of Role. Chinese women have a great deal of responsibility and obligation in society and in their families. On the one hand, women need to go to the community and have their own career. This largely reflects the independence and autonomy of women. In the social life, women bear almost the same responsibilities and obligations as men. However, because of women's special identity of marrying and having children, they often encounter unequal treatment in employment. Employers often give priority to men because of the marriage and childbearing of young women. Some women give up getting pregnant in a short period of time after receiving a decent job because of being afraid to influence their future advancement.

On the other hand, women need consciously to undertake various roles in the family life so that the three family roles of daughter, wife and mother can be balanced with social roles. In the new era, women in China are bearing the double burden of their careers and their families. They often face tremendous physical and psychological pressures. Under these kinds of pressures, women often lose their initial dreams. Therefore, Chinese women still need more attempts and practices in making self-breakthrough.

\section{The Ways for the Women to Achieve Equal and Independent Identity}

To Break the Shackles of Traditional Thinking. In the traditional Confucian ideas, women should be subordinate to men or other authorities. We must affirm the humility and filial piety advocated in Confucianism, but unfortunately it does not provide women with an equally effective mechanism. Although modern women have been well educated and fully integrated into social production, the traditional idea of taking man as core of society also prevails. As long as women in China do not fully realize the true meaning of living for themselves, they have not completely got rid of the traditional shackles. In the face of conservative and outdated traditional practices, Chinese women should have the courage to get rid of the unequal factors and give themselves equal opportunities with men.

With the development of feminism, the life of Chinese women has undergone tremendous changes. Women seek equal rights with men in political, economic, personal and social aspects. 
Chinese women need to break the restrictions of traditional ideas on women's freedom. They should fully understand their own values and abilities in society and in their families so as to maximize their initiatives and achieve equal status with male. Women in today's society have fully possessed the independent personality and economic status. They are fully capable of choosing their own life according to their own wishes without being bound by the worldly customs.

Women's More Rights Given by Society. As an integral part of society, women play a important role in the social and family life. However, women have always been in the disadvantaged group of society and their employment barriers are much higher than that of men. There is a large number of highly educated and highly capable women among graduates. However, the employers prefer to choose male graduates whose ability are less than female. The main reason is that female's future marriage and children will have an impact on their work. Because of the gender difference, men and women cannot get equal opportunities and treatment in their careers. The social security system needs to give working women more benefits. By narrowing this disparity, women can gain more opportunities for fair competition.

In family life, women also need to be given more rights. Women do much more than men in marriage because of the natural motherhood. The law needs to protect the status and interests of women in the family. In western countries, the legal system and welfare system tend to protect the vulnerable groups of women and children. The risk of women's marriage can be reduced by law and policy. In many Western countries, once divorced, women can propose the alimony to their ex-husband after divorce, which not only supports their children but also supports the ex-wives. The improvement in the legal system makes western men devote more energy and cost to marriage, which means that men can share more responsibilities for women. It is obvious that women can get better protection under the condition that the community gives women more rights.

The Integration and Promotion of Chinese and Western Cultures. Although the female consciousness in China started later than that in western countries, and even imitated and followed the basic ideas of the western female consciousness in the early stage, China's female awareness and the status of women's status have developed rapidly since the poliy of reform and opening. While realizing their own values, Chinese women realize their self-worth and work hard together with men to create a harmonious atmosphere in society and in their families.

Due to the different historical and cultural backgrounds, Chinese and Western female consciousness has its own advantages and disadvantages. However, with the interpersonal relations and cultural exchanges in different countries, the female consciousness in China and the West is facing new moral and political ideas. Women need to recognize themselves and achieve self-worth at first. However, the realization of self-worth is more than self-action. It requires the cooperative efforts of women in society as well as in the world. Therefore, women's belief in equality and independence is the same whether they are individualism or collectivism. Only by integrating individualism and collectivism reasonably can we effectively play their respective roles in the pursuit of women's equal rights.

\section{Conclusion}

In today's society, although women's status has risen unprecedentedly in the society and in their families, the responsibilities and duties of women far outweigh their own endurance capacities. It requires the efforts and attempts of women themselves as well as the social attentions to the women's rights and interests during improving women's own status. We need a long-term social practice in the face of realizing women's own value and balancing the responsibility and the obligation. Therefore, female consciousness is always a developing topic whether in China or in western society. Only by truly being liberated from thought and action can women achieve equal status and opportunity with men in order to achieve the ultimate social harmony. Studying the characteristics of Chinese and western female consciousness from the intercultural communication, it is more conducive to mutual exchange and integration and eventually promotes the harmony between women and the world. 


\section{References}

[1] J. Bian, The Similarities and Differences of Chinese and Western Female Consciousness from the Perspective of Intercultural Communication, Northern Literature, 2014(04), pp.75-76. (In Chinese)

[2] M.Yang and RN. Zhou, On the Importance of Women's Economic Independence - Reflections on A Room of One's Own, Shenzhou Magazine, 2013, (6), p.26. (In Chinese)

[3] D. Miller, Celebrating the Feminine: Daoist Connections to Contemporary Feminism in China, Master's Projects and Capstones, 2017, p.613.

[4] BQ. Wu, Differences and Similarities in Chinese and British Cultures from Downton Abbey and A Dream of Red Mansions, Journal of Wuhan Engineering Institute, 2016, (6), pp.55-58. (In Chinese)

[5] D. Li, Confucian Concept of Female, Journal of Hebei Institute of Science and Technology, 2014, (10), p.58. (In Chinese)

[6] XJ. Li, To See Second Sex at the End of the Century, Study, 1999, (12), p.18. (In Chinese)

[7] Peng L, Xiaoping Z. Social Stratification and Cooperative Behavior in Spatial Prisoners' Dilemma Games [J]. PLOS ONE, 2015, 10(7):e0131005. 